\title{
Electrochemical cues regulate assembly of the Frizzled/ Dishevelled complex at the plasma membrane during planar epithelial polarization
}

Matias Simons ${ }^{1}$, William J. Gault ${ }^{1}$, Daniel Gotthardt ${ }^{2}$, Rajeev Rohatgi ${ }^{3}$, Thomas J. Klein ${ }^{1}$, Youming Shao ${ }^{4}$, Ho-Jin Lee, Ai-Luen Wu' ${ }^{5}$, Yimin Fang ${ }^{5}$, Lisa M. Satlin ${ }^{3}$, Julian T. Dow ${ }^{6}$, Jie Chen ${ }^{5}$, Jie Zheng ${ }^{4}$, Michael Boutros ${ }^{7}$ and Marek Mlodzik ${ }^{1}$

Nature Cell Biol. 11, 286-294 (2009); published online 22 February 2009; corrected after print 24 February 2009

In the version of this article initially published, Fig. $5 \mathrm{~s} \mathrm{had} \mathrm{an} \mathrm{erroneous} \mathrm{below.} \mathrm{This} \mathrm{error} \mathrm{has} \mathrm{also} \mathrm{been} \mathrm{corrected} \mathrm{in} \mathrm{the} \mathrm{HTML} \mathrm{and} \mathrm{PDF} \mathrm{versions}$ 8th transmembrane domain on Frizzled. The corrected panel is shown of the article.

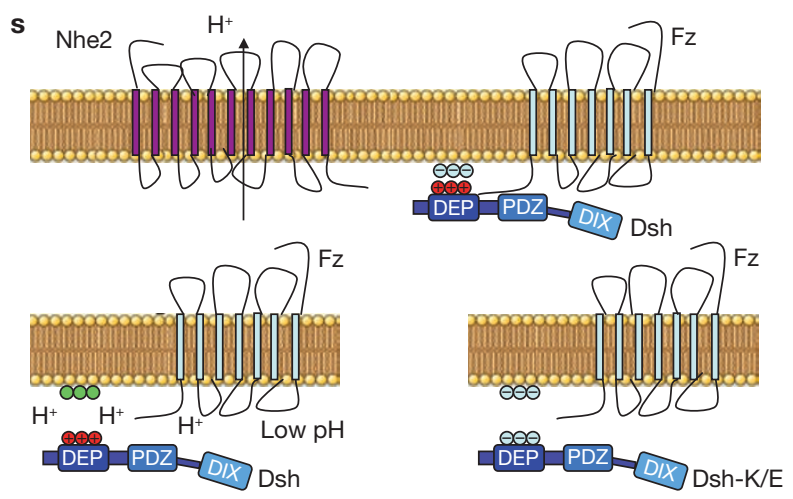

